\title{
Research Article \\ IMPACT OF PINK-PIGMENTED FACULTATIVE METHYLOTROPH ON PHYSIOLOGICAL, GROWTH ANALYTICAL TRAITS AND YIELD OF TOMATO (Solanum lycopersicum) UNDER DROUGHT CONDITION
}

\author{
SIVAKUMAR R*. CHANDRASEKARAN P., SRIVIDHYA S. AND VIJAYAKUMAR M. \\ Regional Research Station, Paiyur, Tamil Nadu Agricultural University, Coimbatore, 641003, Tamil Nadu, India \\ *Corresponding Author: Email- sivatnau14@gmail.com
}

Received: May 14, 2018; Revised: May 24, 2018; Accepted: May 25, 2018; Published: May 30, 2018

\begin{abstract}
An experiment was conducted to assess the impact of Pink Pigmented Facultative Methylotroph and plant growth regulators on alleviating the drought stress effects on tomato through estimating leaf water potential, leaf temperature, stomatal conductance, net assimilation rate, relative growth rate and yield. Pot culture experiment was carried out in tomato variety PKM 1 with foliar spray of PPFM (1\%), PPFM (2\%), PPFM (3\%) and growth regulators like brassinolide (1 ppm), salicylic acid (100 ppm), benzyl amino purine (100 ppm) and gibberellic acid $(10 \mathrm{ppm})$ under drought condition created based on field capacity of soil. 50 per cent field capacity was maintained throughout the growth period for induction of drought and 100 per cent field capacity maintained as non-stress control. Among the PGRs and different concentrations of PPFM used, $2 \%$ PPFM was found to superior in improving drought tolerance. The highest leaf water potential of -0.89 MPa was registered by PPFM $(2 \%)$ which can protect the plant under drought. Foliar spray of $2 \%$ PPFM recorded lowest leaf temperature $\left(25.2^{\circ} \mathrm{C}\right)$ and highest stomatal conductance $(0.40 \mathrm{mmol} \mathrm{m}-2$ $\mathrm{s}-1$ ) followed by brassinolide (25.5 and 0.38 respectively). Brassinolide registered its supremacy on higher net assimilation rate $(0.646)$ followed by $2 \%$ PPFM (0.628). The higher fruit yield of $552.9 \mathrm{~g}$ was maintained by PPFM (2\%) followed by brassinolide (509.4) under drought.
\end{abstract}

Keywords- PPFM, BL, water potential, leaf temperature, NAR, flower abscission, tomato

Citation: Sivakumar R, et al., (2018) Impact of Pink-Pigmented Facultative Methylotroph on Physiological, Growth Analytical Traits and Yield of Tomato (Solanum lycopersicum) Under Drought Condition. International Journal of Microbiology Research, ISSN: 0975-5276 \& E-ISSN: 0975-9174, Volume 10, Issue 5, pp.-1205-1208.

Copyright: Copyright@2018 Sivakumar R, et al., This is an open-access article distributed under the terms of the Creative Commons Attribution License, which permits unrestricted use, distribution and reproduction in any medium, provided the original author and source are credited.

\section{Introduction}

Tomato is an important vegetable crop with good source of vitamins $A, B$ and $C$. The popularity of tomato is rising among consumers because of its high level of lycopene and beta-carotene, which are good anti-oxidants. Although tomato is a day neutral plant, which is highly susceptible to high temperature [1] and drought. According to the fifth assessment report of IPCC (2014), drought is the significant impact of current climate related extremes. In India, drought is a regular problem which affects agriculture frequently. Water is the most limiting factor for plant growth. If plants do not receive adequate water, the resulting drought stress can reduce growth more than all other environmental stresses combined [1]. Drought is the most important environmental stress in agriculture and many efforts have been made to improve crop yield under drought. Foliar application of PGRs can be used to mitigate the negative effect of drought on crops through physiological approaches. Many researches have been conducted on stress mitigating role of brassinosteroids in different plants exposed to various abiotic stresses such as high temperature and drought [13]. Pink-pigmented facultative methylotroph belongs to the genus Methylobacterium and it is an aerobic, gram-negative bacterium. These bacteria are different from others in metabolising methanol and other simpler carbon compounds by living in phyllosphere, the aerial surfaces of plants. The work [4] reported that the PPFM was found superior in improving stress tolerant index and catalase enzyme activity which can protect the plant under abiotic stress condition. Foliar spray of PPFM was found to superior in improving relative water content ultimately improve the drought tolerant capacity in tomato [5]. The group of scientists [6] suggested that the foliar spray of salicylic acid improves drought tolerant capacity of chick pea under drought condition. Cytokinin improves the drought tolerance in different plants through over expression of ipt gene [7]. Hence, the present study was conducted to mitigate the drought effect on tomato by using PPFM and PGRs through assessing water potential, leaf temperature, growth, and yield.

\section{Materials and Methods}

The experiment was carried out in the pot culture under glass house condition. Red sandy soil was used for pot culture experiment. Soil mixture was prepared by using red soil, vermicompost and sand in the ratio of 3:2:1. Drought was imposed at first day after transplanting onwards by maintaining soil moisture at 50 percent field capacity for drought stress. The experiment was laid out in completely randomized block design with three replications and eight treatments viz., absolute control (100\% FC), control (50\% FC), PPFM (1\%), PPFM (2\%), PPFM $(3 \%)$, brassinolide (1 ppm), salicylic acid (100 ppm), benzyl amino purine (100 ppm) and GA3 (10 ppm). Foliar spray of PPFM and PGRs treatments were given at 25 and 45 days after transplanting. Leaf water potential was measured by using an instrument leaf water potential meter (Pressure bomb apparatus - ARIMAD 3000 ) and expressed as -MPa. Stomatal conductance and leaf temperature were measured by using Portable Photosynthesis System (PPS) (Model LI-6400 of LICOR inc., Lincoln, Nebraska, USA) equipped with a halogen lamp (6400-02B LED) positioned on the cuvette. Totally, three measurements were taken in the same leaf. Leaves were inserted in a $3 \mathrm{~cm} 2$ leaf chamber and PPFD at $1200 \mu \mathrm{mol}$ photons $\mathrm{m}-2 \mathrm{~s}-1$, and relative humidity (50-55\%) were set. Net assimilation rate (NAR) was worked out by using following formula described by the scientist [8] and expressed as $\mathrm{mg} \mathrm{cm}-2$ day-1. 
Where,

$$
N A R=\frac{\text { Loge L2 }- \text { Loge } \mathrm{L} 1}{\mathrm{~L} 2-\mathrm{L} 1} \times \frac{\mathrm{W} 2-\mathrm{W} 1}{\mathrm{t} 2-\mathrm{t} 1}
$$

$L 2 \& L 1=L$ eaf area at $\mathrm{L} 2 \& \mathrm{t} 1$ respectively.

W2\& W1 = Plant dry weight at t2\& t1 respectively

t2 - $\mathrm{t} 1$ = Time interval

Relative growth rate was calculated by using following formula [8]

$$
R G R=\frac{\text { LogeW } 2-\text { LogeW1 }}{\mathrm{t} 2-\mathrm{t} 1}
$$

Where, W2 \& W1 are whole plant dry weight at time t2 \& t1 respectively and expressed as g g-1day-1. Abscission study was conducted on single flower basis. Flower number of each plant and dropped flower per each pot were counted every 3 days once. These records were used to calculate the flower abscission and expressed in terms of percentage. The total weight of fruits harvested from each plant of all picking was added and average yield per plant was worked out and expressed in gram per plant. The data on various parameters were analyzed statistically as per the procedure [9]. Wherever the treatment differences are found significant, critical differences were worked out at five percent probability level and the values were furnished.

\section{Results and Discussion}

\section{Impact of PPFM and PGRs on leaf water potential under drought}

Leaf water potential can be considered as a good indicator of leaf water status. Leaf water potential is reduced under water deficit condition. Leaf water potential in the drought treatment was lower than in the control plants [10]. In the present study, the drought-imposed plants showed reduction in leaf water potential due to reduction of soil water potential created by drought [Table-1]. Among the treatments, foliar spray of PPFM (2\%) registered highest leaf water potential $(-0.89$ $\mathrm{MPa}$ ) followed by brassinolide (-0.94 MPa) compared to control (-1.35 MPa). The positive effect of PPFM on leaf water potential can probably be associated with synthesis of compatible osmolytes like proline. Foliar application of PPFM (2\%) increased the proline content by 11.34 percent in tomato [5]. Plant growth regulators like benzyl adenine and brassinolide significantly increased leaf water potential in soybean under water deficit condition [11]. The present study corroborated with earlier findings.

\section{Impact of PPFM and PGRs on stomatal conductance and leaf temperature}

At the onset of stress, extension growth and leaf expansion were first affected, followed by a decrease in rates of stomatal conductance by partial stomatal closure [12]. Soil water content either directly or indirectly influences the plant growth as well as stomatal conductance, since they are mainly turgor depended processes. In the present investigation, drought stress condition caused a remarkable reduction in the stomatal conductance, however, PPFM and PGRs treatments maintained higher stomatal conductance [Table-1]. This condition is attributed to cooling of the leaf surface an account of excessive loss of water through transpiration leading to lesser leaf temperature which helps the plants to tolerate the excessive heat load under drought condition. In the present study, foliar spray of PPFM (2\%) registered higher stomatal conductance $(0.40)$ followed by brassinolide (0.38) compared to control (0.31) and absolute control $(0.45)$. Methylotrophs inoculation was found to increase the stomatal conductance by enhancing the number of stomata, chlorophyll content and malic acid content in sugarcane [13]. The present study confirms earlier findings. The leaf temperature is dependent on climatic parameters and internal plant water status. In the present study, elevation of temperature up to $1.60 \mathrm{C}$ was observed under drought stress condition compared to absolute control [Table-1]. High crop canopy temperature in water-stressed plants may also be related to decrease stomatal conductance and water potential values. The lowest leaf temperature was recorded by absolute control (24.8) and highest was in control (26.4). Foliar spray of PPFM (2\%) recorded less leaf temperature (25.2) followed by brassinolide (25.5) compared to other treatments. The less leaf temperature in the PPFM treated plant might be due to the high stomatal conductance and transpiration rate under drought which helps to reduce the heat load and escape from drought induced high temperature stress. Higher leaf temperature by less stomatal conductance leads to ultimate problem of membrane damage and ROS production may be the reason for lesser yield. PPFM excrete plant growth hormones auxins and cytokinins that influence root growth and help plants to endure water stress. And also, PPFM exude osmoprotectants namely sugars and alcohols on the surface of the plants they reside at. These two properties are believed to help protect the plants from desiccation and high temperatures.

Table-1 Impact of PPFM and PGRs on leaf water potential and gas exchange

\begin{tabular}{|c|c|c|c|c|}
\hline $\begin{array}{l}\mathrm{S} \\
\mathrm{N}\end{array}$ & Treatments & $\begin{array}{l}\text { Leaf water } \\
\text { potential } \\
\text { (-MPa) }\end{array}$ & $\begin{array}{c}\text { Stomatal } \\
\text { conductance } \\
\left(\mathrm{mmol} \mathrm{m}^{-2} \mathrm{~s}^{-1}\right)\end{array}$ & $\begin{array}{c}\text { Leaf } \\
\text { temperature } \\
\left({ }^{\circ} \mathrm{C}\right)\end{array}$ \\
\hline 1 & $\begin{array}{l}\text { Absolute control }(100 \% \\
\text { FC) }\end{array}$ & 0.48 & 0.45 & 24.8 \\
\hline 2 & Control $(50 \%$ FC) & 1.35 & 0.31 & 26.4 \\
\hline 3 & PPFM (1\%) & 1.12 & 0.36 & 25.7 \\
\hline 4 & PPFM $(2 \%)$ & 0.89 & 0.40 & 25.2 \\
\hline 5 & PPFM $(3 \%)$ & 1.14 & 0.35 & 25.8 \\
\hline 6 & Brassinolide (1 ppm) & 0.94 & 0.38 & 25.5 \\
\hline 7 & Salicylic acid (100 ppm) & 1.02 & 0.35 & 25.9 \\
\hline 8 & BAP (100 ppm) & 1.18 & 0.34 & 26.0 \\
\hline 9 & $\mathrm{GA}_{3}(10 \mathrm{ppm})$ & 1.23 & 0.34 & 26.1 \\
\hline \multicolumn{2}{|c|}{ SEd } & 0.025 & 0.016 & 0.65 \\
\hline \multicolumn{2}{|c|}{$\mathrm{CD}(\mathrm{P}=0.05)$} & 0.049 & 0.037 & 1.36 \\
\hline
\end{tabular}
parameters of tomato under drought

\section{Impact of PPFM and PGRs growth analytical traits drought}

Net assimilation rate is an appropriate parameter for the measurement of net photosynthesis of leaves in a crop. In the present study, the highest NAR value of $0.646 \mathrm{mg} \mathrm{cm}-2$ day-1 was recorded by foliar spray of brassinolide followed by PPFM (2\%) which recorded $0.628 \mathrm{mg} \mathrm{cm}-2$ day- 1 and salicylic acid $(0.625 \mathrm{mg} \mathrm{cm}$ 2 day-1) [Fig-1]. Foliar application of 100 ppm salicylic acid significantly increased the leaf area and net assimilation in maize [14]. Foliar spray of $0.1 \mathrm{ppm}$ brassinosteroid increases net assimilation rate in blackgram [15]. Present study confirms the earlier findings.

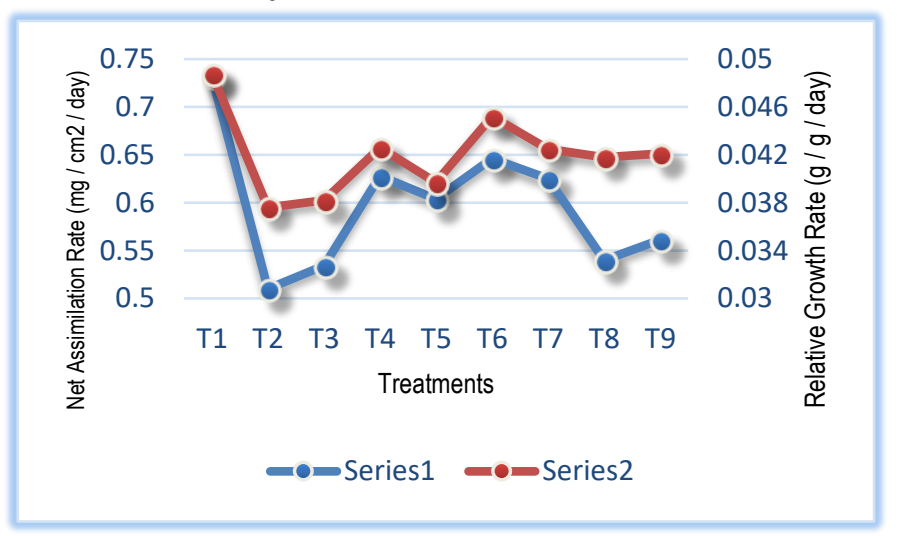

Fig-1 Impact of PPFM and PGRs on NAR and RGRof tomato under drought

T1: Absolute control (100\% FC); T2: Control (50\% FC); T3: PPFM (1\%); T4: PPFM (2\%); T5: PPFM (3\%); T6: Brassinolide (1 ppm); T7: Salicylic acid (100 ppm); T8: BAP (100 ppm); T9: GA 3 (10 ppm)

It has been shown that microbes of the genus Methylobacterium produced cytokinin [16] which delays the senescence of leaves under drought. The "classical" phyto-hormone auxin is also produced and secreted by different strains of Methylo-bacterium [17]. The first time reported the production of gibberellic acid by Methylo-bacterium $\mathrm{sp}$. which acted as plant growth regulator by modifying plant morphology [18]. The scientist [19] observed that the zeatin production ranging from 0.07 to $1.84 \mu \mathrm{g} / \mathrm{ml}$ by PPFM. These results clearly indicated that the production and release of important growth promoting substances by nonpathogenic Methylobacteria which might have been involved in the regulation of plant growth and highly correlated with drought tolerance. Relative growth rate is a growth analytical trait used to measure the ability of the plant to produce new plant material, referred to as efficiency index. 
In the present study, about $22.95 \%$ reduction RGR was observed under drought condition compared to non-stress condition [Fig-1]. However, foliar spray of brassinolide and PPFM maintained the RGR under drought condition. Among the treatments, brassinolide showed its supremacy on relative growth rate $(0.0452)$ followed by PPFM (0.0426) and salicylic acid (0.0425). Foliar spray of Glomus mosseae and 24-Epibrassinolide could alleviate the adverse effects of salinity by improving relative water content (RWC) of leaves $(62 \%)$ and relative growth rate $(40.74 \%)[20]$.

\section{Impact of PPFM and PGRs on flowering and yield of tomato under drought}

The reproduction is the crucial phenomenon to be affected by any abiotic stress in any crop. An increase in the frequency of water stress during flower development affects plant reproduction with immediate and long-term effects [21]. Drought induced high temperature stress is one of the most important causes of change in plant morphology, physiology and biochemical aspects, which reduces plant growth and development in this particular vegetable crop. High temperature during reproductive development was reported to induce early flower bud initiation with significant increment in flower drop [22]. In the present study, drought increased the flower abscission up to $21.25 \%$ compared to absolute control $(9.66 \%)$. However, the less flower drop percentage was noticed in foliar spray of PPFM and plant growth regulators (Fig-2).

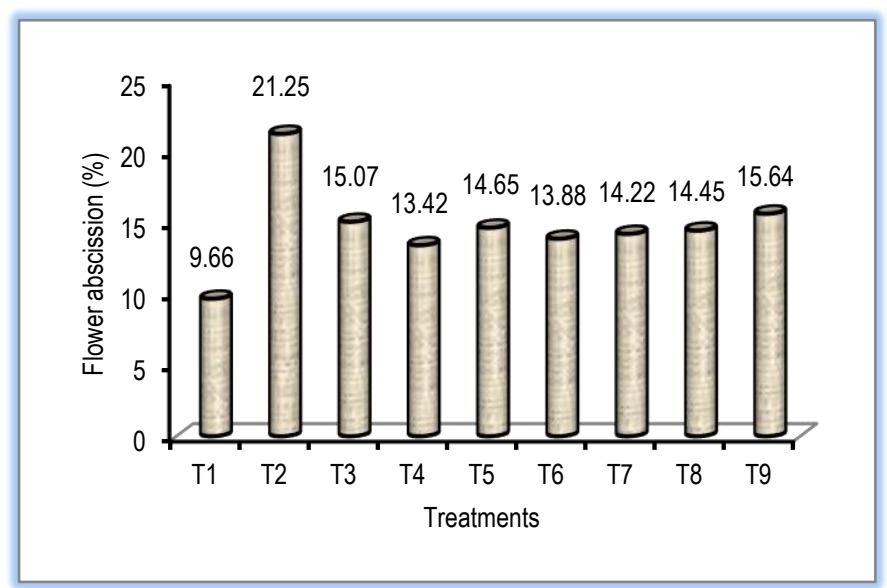

Fig-2 Impact of PPFM and PGRs on flower abscission of tomato under drought T1: Absolute control (100\% FC); T2: Control (50\% FC); T3: PPFM (1\%); T4: PPFM (2\%); T5: PPFM (3\%); T6: Brassinolide (1 ppm); T7: Salicylic acid (100 ppm); T8: BAP (100 ppm); T9: GA $3(10 \mathrm{ppm})$

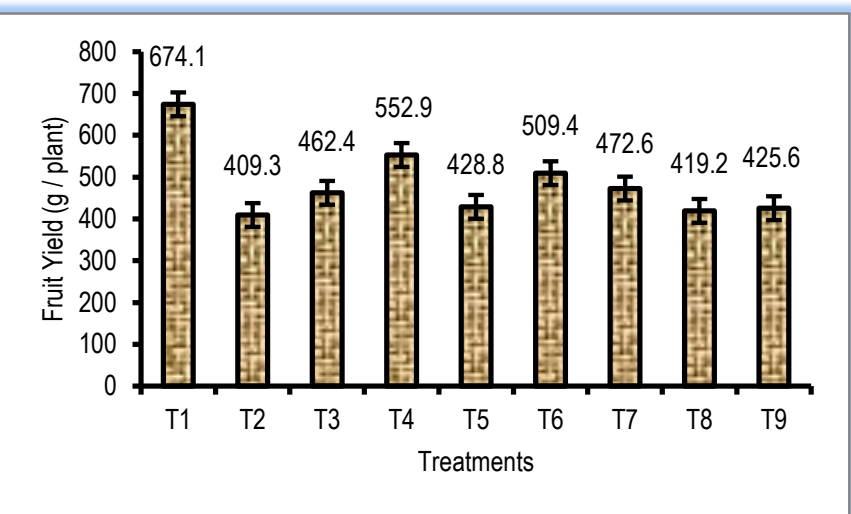

Fig-3 Impact of PPFM and PGRs on fruit yieldof tomato under drought

T1: Absolute control (100\% FC); T2: Control (50\% FC); T3: PPFM (1\%); T4: PPFM (2\%);

T5: PPFM (3\%); T6: Brassinolide (1 ppm); T7: Salicylic acid (100 ppm); T8: BAP (100 ppm); T9: GA 3 (10 ppm)

Lower flower abscission by the PPFM and PGRs might be due to the maintenance of photosynthesis and efficient translocation of photosynthates to the reproductive parts under drought. The reduction in photosynthesis during stress may decrease the availability of assimilates to the developing floral organs and leads to the abscission of flowers and flower buds. However, there was an opinion that the abortion of reproductive organs is not solely due to a shortage of assimilate supply but also due to other factors such as assimilate utilization [23]. Drought induced high temperature also causes bud and flower drop up to $42.56 \%$ in the tomato [21]. Absolute control significantly recorded the highest fruit yield of $674.10 \mathrm{~g}$ and control recorded the least value of $409.3 \mathrm{~g}$. Foliar spray of $2 \%$ PPFM documented significantly superior fruit yield of $552.90 \mathrm{~g}$ which is closely followed by brassinolide $(509.40 \mathrm{~g})$ and salicylic acid $(472.60 \mathrm{~g})$. Drought is a serious environmental stress which affects agriculture productivity and yield more than 50 per cent [24]. In the present study, $64.70 \%$ of yield was reduced by drought stress (Fig-3). Water stress inhibits cell enlargement and cell division ultimately reduces plant growth by affecting various physiological and biochemical processes. Yield showed positive response to PPFM and PGRs under water deficit condition. PGRs help in mitigation of water stress and reduced the percent reduction in yield in wheat [25]. In the present study, fruit yield increased up to 35.00 percent by PPFM $(2 \%)$ followed by brassinolide $(24.50 \%)$.

\section{Conclusion}

Foliar spray of $2 \%$ PPFM on tomato at 25 and 45 days after transplanting maintained the leaf water potential and leaf temperature under drought. It is also reduced flower drop percentage and increased the fruit yield up to 35 percent compared to control.

\section{Applications of Research}

1. This finding is valuable for drought mitigation technology for tomato

2. Suitable concentration of PPFM for alleviation of drought on tomato was identified

\section{Research Category: Drought mitigation technology}

\author{
Abbreviations: \\ PPFM - Pink pigmented facultative methylotroph \\ PGRs - Plant growth regulators \\ $\mathrm{BL}$ - Brassinolide \\ GA3 - Gibberellic acid
}

Acknowledgement / Funding: Author thankful to Department of Crop Physiology, Tamil Nadu Agricultural University, Coimbatore, 641003, Tamil Nadu, India for providing Glass house, pots and labours for timely completion of Research work.

\section{${ }^{*}$ Research Guide or Chairperson of research: Dr. R. Sivakumar}

University: Tamil Nadu Agricultural University, Coimbatore, 641003, Tamil Nadu Research project name or number: Nil

\section{Author Contributions: All author equally contributed}

Author statement: All authors read, reviewed, agree and approved the final manuscript

\section{Conflict of Interest: None declared}

Ethical approval: This article does not contain any studies with human participants or animals performed by any of the authors.

\section{References}

[1] Malik M. and Bashir E. (1994) Horticulture. National Book Foundation, USA.

[2] Khan S.H., Khan A., Litaf U., Shah A.S., Khan M.A., Bilal M. and Ali M.U. (2015) Journal of Food Processing and Technology, 6 (7), 465470.

[3] Mahesh B., Parshavaneni B., Ramakrishna B. and Rao S.S.R. (2013) American Journal of Plant Sciences, 4, 2305-2313.

[4] Chandrasekaran P., Sivakumar R., Nandhitha G.K., Vishnuveni M., Boominathan P. and Senthilkumar M. (2017) International Journal of Current Microbiology and Applied Sciences, 6 (6), 540-549. 
[5] Sivakumar R., Nandhitha G.K., Chandrasekaran P., Boominathan P. and Senthilkumar M. (2017) International Journal of Current Microbiology and Applied Sciences, 6 (6), 1640-1651.

[6] Farjam S., Siosemardeh A., Kazemi-Arbat H., Yarnia M. and Rokhzadi A. (2013) Journal of Applied Botany and Food Quality, 87, 80-86.

[7] Peleg Z., Reguera M., Tumimbang E., Walia H. and Blumwald E. (2011) Plant Biotechnology Journal, 9, 747-758.

[8] Williams S.R.F. (1946) Methods of growth analysis. In: Plant photosynthetic production manual methods (Sestak, Z., J. Catasky and P. J. Jouris (eds). Drow, JenkN.U.Publishers. The Hague, 348391.

[9] Gomez K.A. and Gomez A.A. (1984) Statistical procedures for agricultural research. (2nd Ed.) John Wiley and Sons, New York, USA.

[10] Suresh K., Kumar M.K., Kantha D.L., Lakshmi R.P. and Sunil Kumar K. (2012) Indian Journal of Plant Physiology, 17 (3\&4), 233-240.

[11] Zhang M., Zhai Z. Tian X. Duan L. and Li Z. (2008) Plant Growth Regul., 56, 257-264.

[12] Chartzoulakis K., Noitsakis B. and Therios I. (1993) Irrigation Science, $14,1-5$.

[13] Cervantes-Martinez J., Lopez-Diaz S. and Rodriguez-Garay B. (2004) Plant Science, 166, 889-892.

[14] AminA.A., Abd El-Kader A., Magda A.F., Shalaby,Fatma A.E., GharibEl-Sherbeny M., Rashad A. and Jaime A. (2013) Communications in Soil Science and Plant Analysis, 44, 1141-1155.

[15] Krishna Surendar K., Vincent S., Mallika Vanagamudi and Vijayaraghavan H. (2013) Bulletin of Environment, Pharmacology and Life Sciences, 2 (4), 70-76.

[16] Koenig R.L., Morris R.O. and Polacco J.C. (2002) Journal of Bacteriology, 184, 1832-1842.

[17] Hornschuh M., Grotha R. and Kutschera U. (2002) Plant Biology, 4, 682-687.

[18] Anurajan S. (2003) M.Sc. (Agriculture) Thesis, Tamil Nadu Agricultural University, Coimbatore

[19] Jones N.P. (2010) Ph.D. (Agriculture) Thesis, University of Agricultural Sciences, Dharwad.

[20] Ramazan A.K., Farzaneh N., Khadijeh R. and Farhad R. (2017) Physiology and Molecular Biology of Plants, 23 (3), 557-564.

[21] Srivastava K., Kumar S., Prakash P. and Vaishampayan A. (2012) Sabrao Journal of Breeding Genetics, 44 (2), 263 - 276.

[22] Wang W., Vinocur B. and Altman A. (2003) Planta, 218, 1-14.

[23] Aloni B., Karni L., Zaidman Z., Riov Y. and Schaffer A. (1996) Annals of Botany, 78, 163-168.

[24] Wang W., Vinocur B. and Altman A. (2003) Planta, 218, 1-14.

[25] Shah N.H. and Paulsen G.M. (2011) Plant Soil, 257, 219-226. 